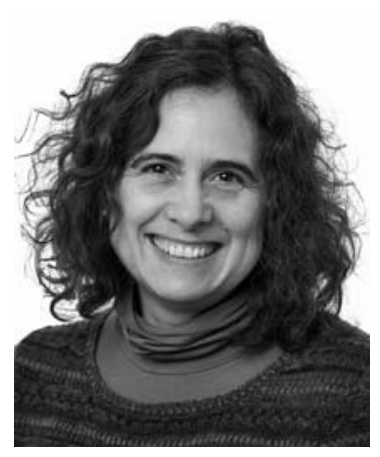

\title{
A Conversation with Anne Ferguson-Smith
}

\author{
INTERVIEWER: JAN WITKOWSKI \\ Executive Director, Banbury Center at Cold Spring Harbor Laboratory
}

Anne Ferguson-Smith is Head of Department of Genetics at the University of Cambridge.

Jan Witkowski: Tell me a bit about your work.

Dr. Ferguson-Smith: We work on genomic imprinting, which is a remarkable process that causes genes to be expressed from only one of the two parental chromosome homologs. We're currently interested in the mechanism of imprinting and how the epigenetic process that regulates it acts to remember the parental origin of the two parental chromosomes and how that memory is actually maintained. There is a dramatic genome-wide loss of epigenetic marks during the preimplantation phase of very early embryonic development in mammals, and we don't know why that happens. If that reprogramming event hits the imprints, it would result in the loss of the memory of the parental origin of the two chromosomes. We're interested in the mechanism that allows imprints to be refractory to these reprogramming events that happen in the early embryo.

Jan Witkowski: Why are there epigenetic marks at imprints in the first place?

Dr. Ferguson-Smith: There are two parental chromosome homologs that for all intents and purposes have an identical DNA sequence, but imprinting turns on genes on one of them and not the other, so it has to be a nongenetic mechanism, an epigenetic mechanism. I call it "genetics with knobs on." This is a mark that differentiates the two parental chromosomes and allows the transcriptional machinery to turn one of the alleles on while retaining the other in an "off" state. This is regulated by epigenetic machinery that initiates DNA methylation of the parental chromosomes differently in the two parental germlines. These two chromosomes start with a methylation mark that is different on the maternally inherited chromosome than the paternally inherited one, and that is read differently by the transcriptional machinery.

Jan Witkowski: The best example is presumably X inactivation. You don't want two Xs working in the female and just one $\mathrm{X}$ in the male, so the female silences one $\mathrm{X}$. But for autosomal genes, why does one need to imprint?
Dr. Ferguson-Smith: In the context of $\mathrm{X}$ inactivation, it actually is a whole chromosome that is silenced but in autosomal imprinting it's a relatively small subchromosomal domain. We don't know why this process evolved. What is the selective advantage to turn off genes on only one of your parental chromosomes? What is the functional relevance of controlling gene dosage by this mechanism?

Many of these imprinted genes are exquisitely dosagesensitive, and there are some instances where there is a selective absence of imprinting of these genes in particular developmental niches. We've been working on a gene that is canonically imprinted most places except in a neurogenic niche in the adult brain, where it turns on the other repressed allele because it needs a double dose. It seems that it's quite important to be able to modulate gene dosage in this way, and in this case it's by turning off a gene on one of the two parental chromosomes, or turning it on again in a context where you need more of it.

Jan Witkowski: You've also worked on imprinting and release of marks during oogenesis and spermatogenesis.

Dr. Ferguson-Smith: Several years ago in collaboration with John Li and Phil Leder we identified a protein called Zfp57, which is a KRAB (Krüppel-associated box) zinc finger protein. There are hundreds of KRAB zinc finger proteins in vertebrate genomes, and they seem to be quite rapidly evolving. They seem to target the epigenetic machinery and silence particular regions of the genome. In particular, they seem to have evolved to silence endogenous retroviral sequences. One of them is required for silencing imprints by targeting repressive epigenetic states. It raises some interesting issues. For example, is there a relationship between an imprint and an endogenous retrovirus? They do have many features in common, one of which being its ability to recruit these KRAB zinc finger proteins that have the potential to recruit epigenetic states.

Jan Witkowski: Zfp57 is involved in indicating which genes need to be imprinted? 
Dr. Ferguson-Smith: Actually, it seems to be maintaining a mark that is already there. The mark comes in from the germline; the KRAB zinc finger protein doesn't play a role in the establishment of that mark. It does, however, make sure that the mark is maintained during the preimplantation period when other methylation marks are being lost.

Jan Witkowski: Does it make sure the marks get put back on or are they not released in the first place?

Dr. Ferguson-Smith: We're still trying to tease apart those details. I think it's targeting marks back on in a replication-dependent manner, although it might also protect from active demethylation as well. Zfp57 binds not only in a sequence-specific manner, but also in a methylation-sensitive-specific manner. It notices when the region is methylated and binds to the methylated copy, and makes sure that after replication that methylated copy is maintained.

Jan Witkowski: Does a knockout of this protein produce embryonic lethality?

Dr. Ferguson-Smith: The protein is required to be present in the egg on fertilization, but you also require the zygotic genome to synthesize it too. When both these things happen you have enough to retain good proper imprints. When you knock out both the maternally loaded Zfp57 and the zygotic form, you lose methylation memory and the embryos die.

Jan Witkowski: Is this dose dependent?

Dr. Ferguson-Smith: Heterozygote mutants are all right. If you don't have it loaded in the egg but you do turn it on in a zygote the animals don't die, but if you have it in the egg and fail to have it in the zygote they do die; you have a partially penetrant lethality and lose some of the imprints. There is a dosage effect, particularly during that very early period, which is required for ensuring proper memory. You can lose that memory a little bit, and that results in a chimeric epigenetic state where some cells have it and some don't.

Jan Witkowski: For any given imprinted gene, is it always found imprinted on the same parental chromosome?

Dr. Ferguson-Smith: Yes, that's one of its characteristic features. It's always expressed from the same parental chromosome homologue and not the other. This differs from random monoallelic expression, which is what you see in X inactivation, which is a random event. The imprinted gene is always expressed from either the paternally inherited chromosome or from the maternally inherited chromosome. There are no examples that I'm aware of where you have a switch from one to the other, but there are imprinted genes that have isoforms that are expressed from one parental chromosome homolog and another isoform that is expressed from the other chromosome.

Jan Witkowski: So the same gene on the two chromosomes is marked differently?
Dr. Ferguson-Smith: Yes. If it's a mechanism to regulate dosage, why would you care about parental origin? I think this is about the evolution of the mechanism and understanding what it is about the paternal and maternal germlines that allow it to place methylation marks in different places that are then subsequently heritably maintained in the offspring. We have to look very carefully at the differences between maternally derived marks and paternally derived marks, and there are some patterns. Maternally derived marks are always at promoters, and the methylation marks are obviously promoters either of the imprinted gene itself or at a long noncoding RNA that regulates a cluster of imprinted genes.

The paternally derived ones are somewhere else. They're never at promoters. There are only three of them, and they're all intergenic. That might be because of the timing of when these methylation marks are put on. In the female germline, a methylation mark is put on in a growing oocyte after replication. It's not going to divide and make more eggs. Whereas in the male germline, that mark is placed earlier during fetal development at a time when there is still going to be considerably more replication of these male germ cells. DNA methylation is a mutagen, so you don't want to put methylation on at a promoter in a male germline because you could potentially inherit a germline mutation in these very important regulatory regions. That might be one reason.

The other reason, which is very speculative, is that the male and female germlines have very different agendas in their epigenetic acquisition. For example, when Tim Bestor and Déborah Bourc'his knocked out the machinery that puts methylation marks on imprints in the male germline, the cells arrested at the pachytene stage. They basically couldn't do meiosis. This meiotic arrest renders the male infertile. In the female germline, that's not true. If you screw up the machinery that puts imprints on, you just screw up imprints. That suggests that the two parental genomes have different agendas in what they're doing with the epigenetic marks that regulate imprinting. I think that has important evolutionary implications for the process of imprinting.

Jan Witkowski: Is imprinting restricted to mammals, to vertebrates? Do invertebrates have a similar phenomenon?

Dr. Ferguson-Smith: It's a very recent phenomenon that's evolved in mammals. Plants do something similar. They have bona fide imprinted genes, but not as many, and the mechanism is thought to have evolved independently from that of mammals. As a mammalian-specific phenomenon, you see the acquisition of imprinting over evolutionary time. There are a couple of hundred imprinted genes in eutherian mammals. None have been identified in oviparous mammals - the platypus or the echidna. In marsupial mammals, a very small subset of imprinted genes found in eutherians is also found in marsupials. Imprinting has evolved at particular loci as the need has arisen over evolutionary time. 
Jan Witkowski: Snakes get on quite well without any imprinting at all.

Dr. Ferguson-Smith: That's right, and many organisms can reproduce parthenogenetically. Of course, one reason you can't have parthenogenetic mammals is because of imprinting, because you need a set of chromosomes from the male to get the proper transcriptional complement. 


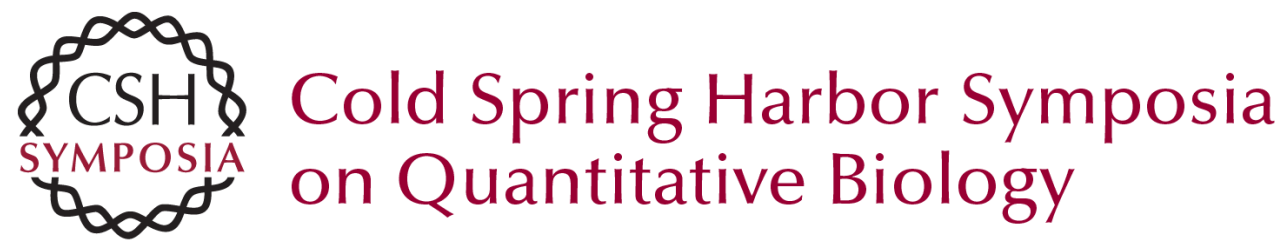

\section{A Conversation with Anne Ferguson-Smith}

Cold Spring Harb Symp Quant Biol 2015 80: $321-323$

Access the most recent version at doi:10.1101/sqb.2015.80.029983

\section{License}

Email Alerting Receive free email alerts when new articles cite this article - sign up in Service the box at the top right corner of the article or click here. 